\title{
Mobile Harbor Crane Wheel Hub Fatigue Failure
}

\author{
J. Shirokoff
}

(Submitted 23 December 2002; in revised form 7 January 2003)

Failure analysis of a mobile harbor crane wheel hub demonstrated that the mechanism of failure was fatigue. The wheel hub was a ductile cast iron component that had been subjected to cyclic loading during a ten-year service period. The fracture surface of the fatigue failure also contained corrosion deposit, suggesting that cracking occurred over a period of time sufficient to allow corrosion of the cracked surfaces. Replacement and alignment of the failed wheel hub is recommended along with inspection of the nonfailed wheel hubs that remain on the crane.

Keywords: cast iron, corrosion, ductile, EDS, fatigue, SEM

\section{Introduction}

A large mobile harbor crane commissioned in the early 1990s operated for more than ten years. Operations included lifting containers off ships and tractor-trailer transportation vehicles. Generally, the crane operates in a stationary, fixed-and-anchored position; however, on one occasion when it was mobile the crane experienced a wheel hub failure. The crane was being moved to a new location on the docks when the failure occurred. The crane has six axles, weighs approximately 345 tons, and is driven in a mobile mode during relocation processes. Approximately $1 / 6$ of the 345 ton load (57.5 tons) is carried by each axle. The failure occurred when the crane was making a turn down a gradual paved slope. This turn and accompanying downward motion increased the stress on the wheels on one

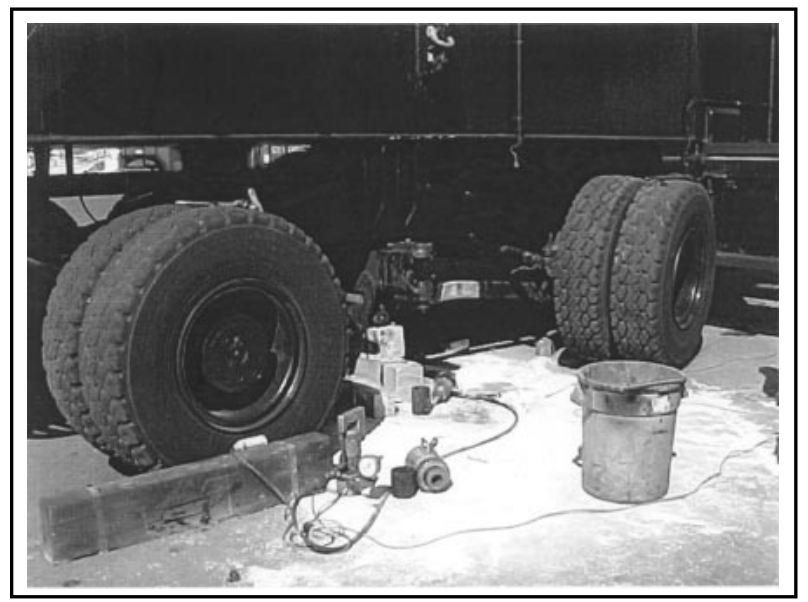

Fig. 1 General view of two crane wheel sets and one failed axle (middle) with wheel and wheel hub removed. The wheels are turned at different angles. side of the crane, and one of the six wheel hubs on that side of the crane failed. The wheel failure led to an axle failure while the crane was still moving. The failed wheel was the second in line and the leading drive wheel for the crane (the drive wheels are the second and third wheels in line).

A general view of two of the six axles and their wheels along the side of the crane is shown in Fig. 1. In between the two axle/wheel assemblies is the failed axle with wheel assemblage removed. The photograph in Fig. 2 shows an axle, wheel hub, wheel, tire, and steering arm of an axle assemblage that is in good working order.

\section{Experimental}

Several test methods were employed to evaluate the failed wheel hub. The fracture surfaces on sections of the failed wheel hub were examined

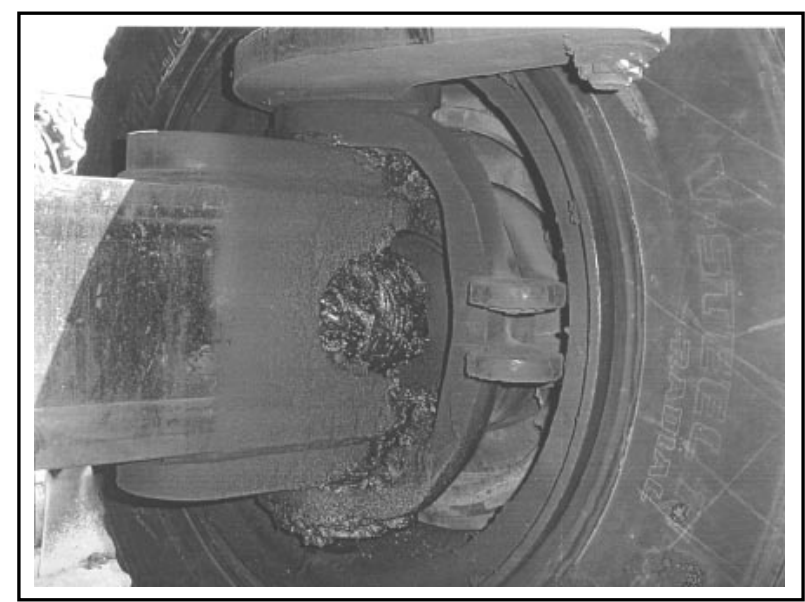

Fig. 2 View of a nonfailed axle, wheel hub, and steering arm (top)

J. Shirokoff, Associate Professor of Engineering, Faculty of Engineering and Applied Science, Memorial University of Newfoundland, St. John's, NF, Canada A1B3X5. Contact e-mail: shirokof@engr.mun.ca. 
visually and with a scanning electron microscope (SEM). A piece of the failed wheel hub was chemically tested and metallographically sectioned to verify the material and metallurgical microstructure. An energy-dispersive spectroscopy (EDS) system attached to the SEM provided elemental analysis for elements sodium and higher on the periodic table. Carbon analysis was performed using an element analyzer connected to an isotope ratio mass spectrometer. Ultrahigh-purity helium was used as a carrier gas for the carbon analysis. Optical metallography was performed on polished and etched (5\% nital) samples from the failed wheel hub. Similar samples were used for microhardness measurements.

\section{Results and Discussion}

The microstructure of the wheel hub was spheroidal graphite dispersed in a ferrite metal matrix. This microstructure is typical of a ductile cast iron (also known as nodular iron). ${ }^{[1]} \mathrm{A}$ micrograph of the wheel hub microstructure near a fractured surface is shown in Fig. 3. This microstructure is representative of the entire component (nearfracture areas and bulk metal), thus suggesting the local variations in microstructure did not contribute to the failure process. Elemental analysis of the metal wheel hub using EDS on the SEM revealed that the primarily iron alloy contained $1.328 \mathrm{wt} . \%$ silicon (Fig. 4), and the carbon analysis (3.57 wt.\%) was within the range of 3.5 to $3.8 \%$ reported for nodular iron. ${ }^{[1]}$

The average Vickers hardness number (VHN) of the polished and etched samples was 137. This

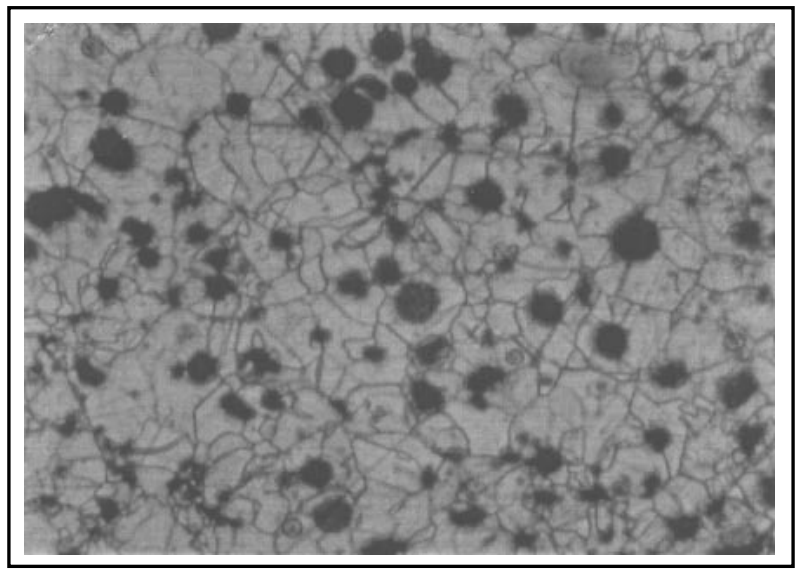

Fig. 3 Optical metallograph of ductile cast iron showing the spheroidal graphite phase in a ferrite matrix. 250x hardness converts to a Rockwell B hardness of 74 and corresponds to a tensile strength of approximately 65,000 psi (448.3 MPa). This tensile strength is consistent with the tensile strength of 55,000 to 70,000 psi $(380 \text { to } 480 \mathrm{MPa})^{[1]}$ gener-

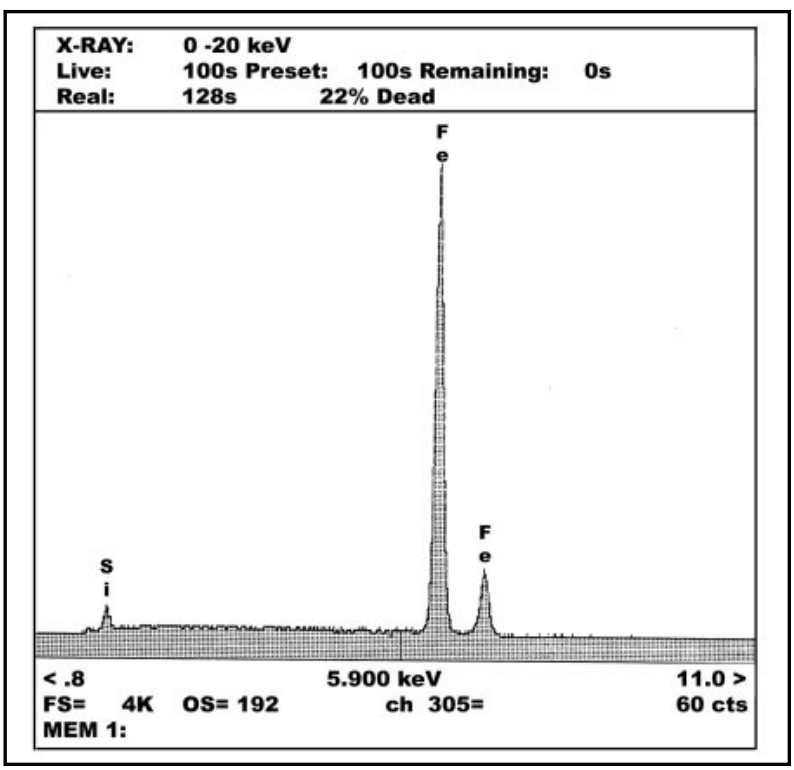

Fig. 4 Energy-dispersive spectroscopy of the ductile cast iron

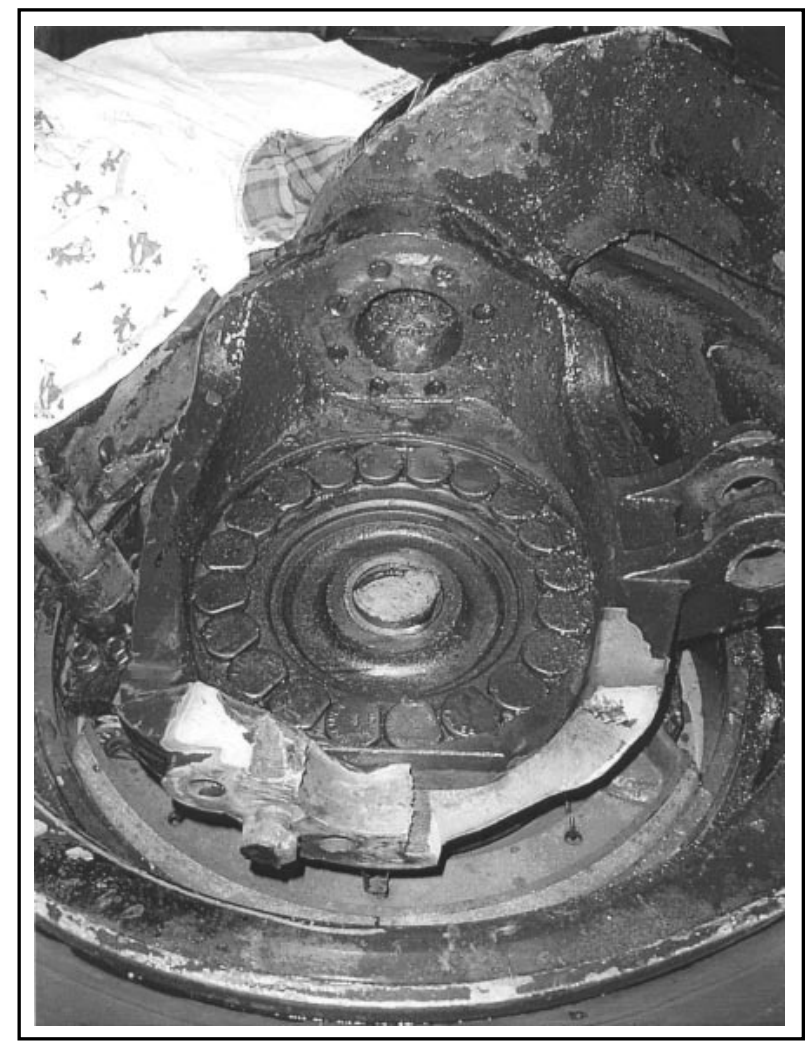

Fig. 5 Failed wheel hub (side view) showing fracture surface and area where material has broken away 
ally reported for ferritic ductile (nodular) iron. Therefore, the microstructure, chemical analysis, and hardness test/tensile strength confirm that the wheel hub was made from the appropriate material, a ductile cast iron.

The failed wheel hub and axle are shown in Fig. 5. Much of the fracture surface appears rough and granular, consistent with macroscopic appearance of overload fracture. Such fracture would occur after the load-carrying capabilities of the component had been reduced by the presence of fatigue cracks. ${ }^{2]}$ Additional examples of overload fracture are presented in Fig. 6, where a side view of the fractured wheel hub components are shown. Another smoother, flatter, and less shiny region of the fracture surface is shown in Fig. 7. Regions on this portion of the fracture appear as brown stains (arrow). The brown area was chemically analyzed by EDS on the

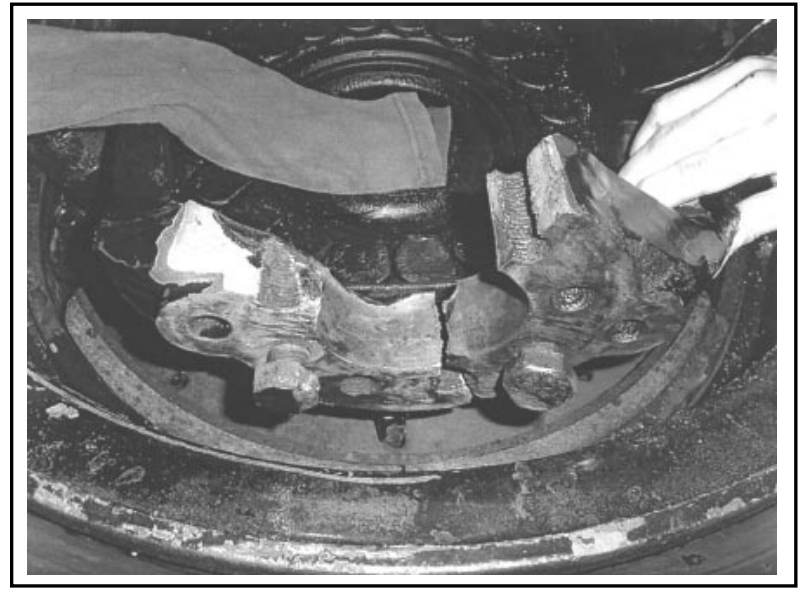

Fig. 6 Failed wheel hub (side view) incorporating the broken part held in place

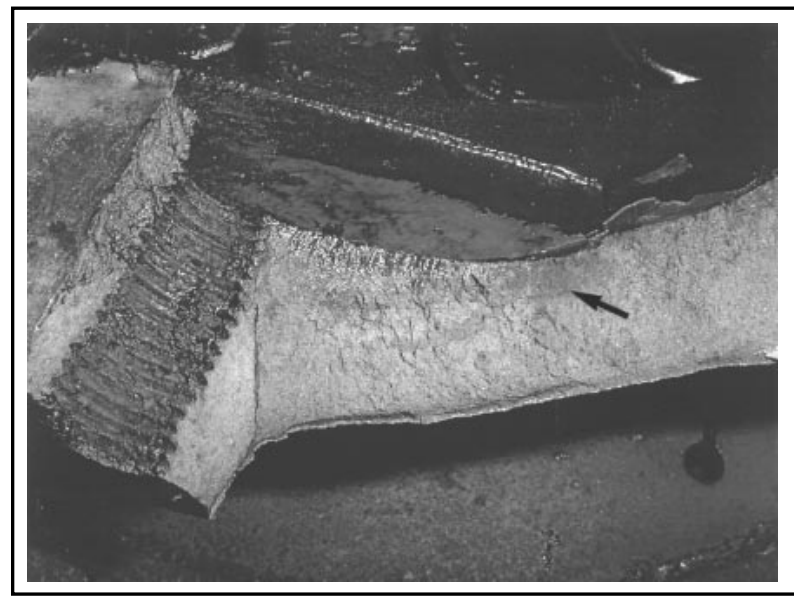

Fig. 7 Fracture surface of the failed wheel hub showing the brown discoloration or stain area (arrow)
SEM and found to be primarily iron with a minor presence of sodium, silicon, sulfur, chlorine, potassium, calcium, manganese, and zinc. The brown stain is assumed to be primarily iron oxide (the EDS system does not capture $\mathrm{X}$-ray emissions from oxygen). Scanning electron microscopy fractograph and optical fractograph of the flat oxidized portions of the fracture surface (Fig. 9 and 10) are consistent with a ductile fatigue fracture failure without the presence of fatigue striations. ${ }^{[3,4]}$ These fracture features are also consistent with the lack of embrittlement in the nodular cast iron. ${ }^{[5-7]}$

The state of stress on the crane wheel hubs is typically one of compression when the crane is not in motion. During crane relocation (driving motion

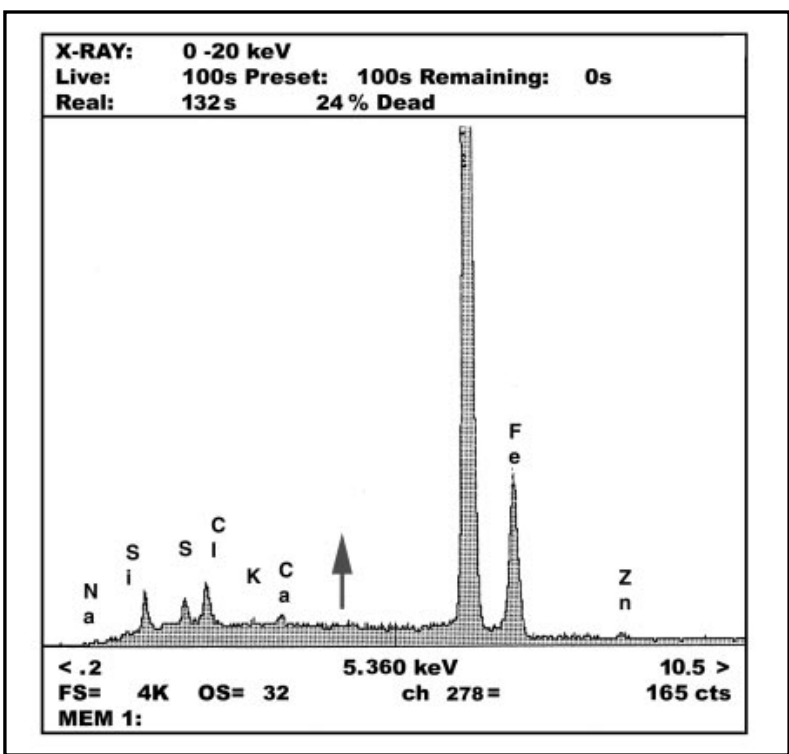

Fig. 8 Energy-dispersive spectroscopy of the discolored surface of Fig. 7

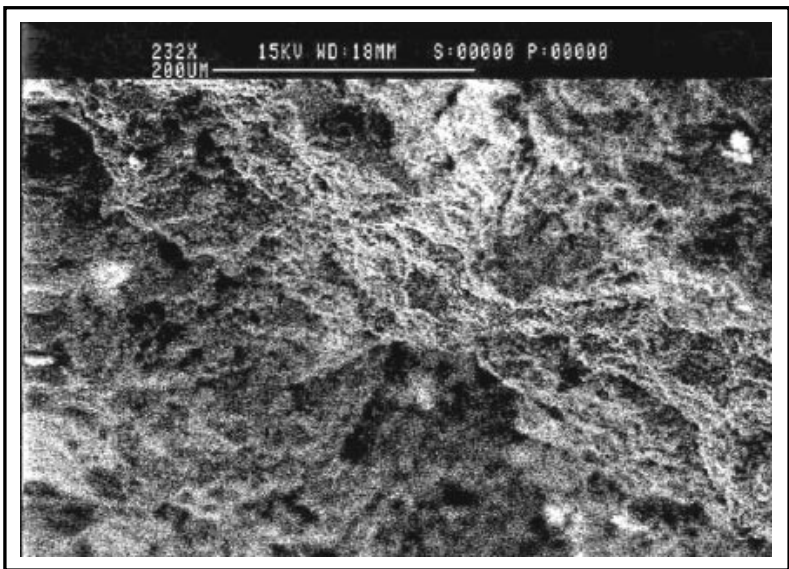

Fig. 9 Scanning electron microscopy micrograph of the fracture surface 


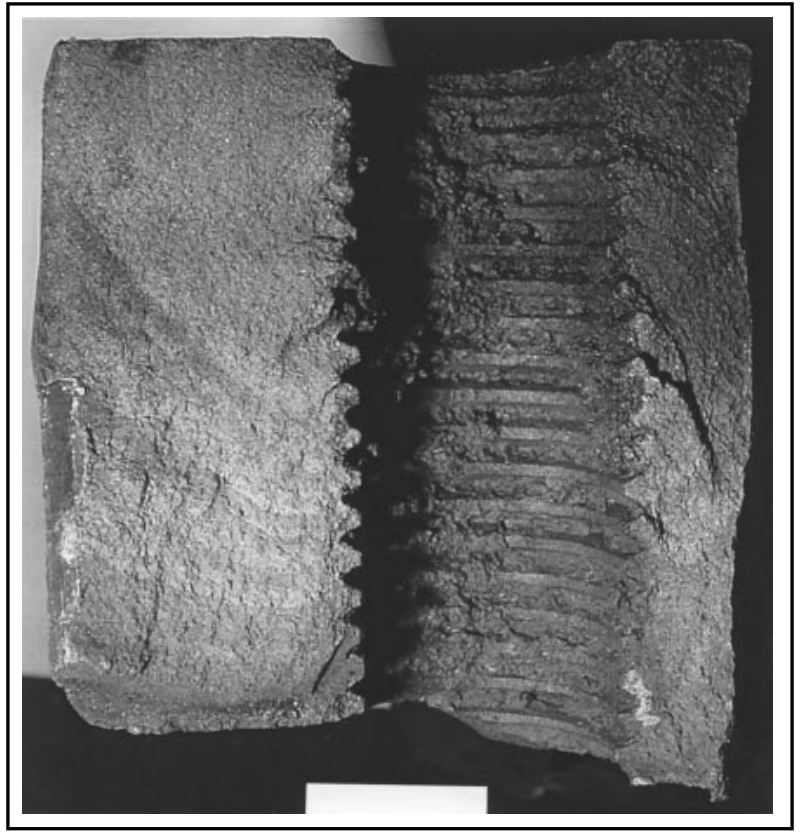

Fig. 10 Fractograph of the wheel hub fatigue failure

of the crane), the addition of forward and lateral (centrifugal) forces are operating. These additional stresses, if great enough, could lead to overloading the allowable design stress of the wheel hub and result in a failure, or overloading the wheel hub after it has experienced some weakening due to the presence of fatigue cracks and the resulting stress raisers.

The crane has a gross weight of 345 tons distributed over six axles carrying approximately $1 / 6$ of the load, or 57.5 tons each. The turning motion down a slope would provide a lateral stress to the hub, while the driving axles would torque the wheels. The wheel hub is made of ductile cast iron, a material generally selected for its strength in compression, damping characteristics, and cost. The presence of an oxidized fatigue fracture surface, coupled with the rougher morphology of the overload fracture regions, suggests that the fatigue crack developed during prior service and concentrated the stresses generated by crane motion. When the stress concentration (the combined effects of crack length and motion-induced stresses) reached a critical value, the wheel hub failed.

\section{Conclusions}

The wheel hub failure was due to the serviceinduced growth of a fatigue crack and stressconcentrating effects of that crack on motioninduced stresses. The cause(s) of fatigue crack initiation and growth was(were) not established, but misalignment of the hub is considered a likely candidate.

\section{Recommendations}

1. A new nodular cast iron wheel hub and axle should be used to replace the failed component.

2. The installation process should assure that the new wheel hub and axle are properly aligned.

3. The nonfailed wheel hubs should be examined for cracks using traditional inspection methods such as liquid dye penetrant.

4. A more detailed analysis of wheel hub stresses may be beneficial, especially if any additional cracks are found in the nonfailed assemblies. This analysis would require data and engineering drawings of the wheel hub assemblage from the crane manufacturer and could incorporate stress measurement of the wheel hub using strain gages.

\section{References}

1. W.D. Callister, Jr.: Materials Science and Engineering: An Introduction, $5^{\text {th }}$ ed., John Wiley \& Sons, 2000, pp. 365-67.

2. R.E. Reed-Hill: Physical Metallurgy Principles, $2^{\text {nd }}$ ed., D. Van Nostrand Co., New York, 1973, pp. 810-11.

3. P.F. Thomason: Ductile Fracture of Metals, Pergamon Press, Oxford, 1990, pp. 1-29.

4. R.M. Thomson: Physical Metallurgy, $3^{\text {rd }}$ ed., R.W. Cahn and P. Haasen, Ed., Elsevier Science Publ. BV, 1983, pp. 1487-551.

5. C.R. Brooks and A. Choudhury: Metallurgical Failure Analysis, McGraw-Hill, Inc., 1993, pp. 119-269.

6. S. Kocanda: Fatigue Failure of Metals, Sijthoff and Noordhoff Int. Publ., Warsaw, 1978, pp. 269-362.

7. V.J. Colanjelo and F.A. Heiser: Analysis of Metallurgical Failures, $2^{\text {nd }}$ ed., John Wiley \& Sons, 1987, pp. 133-61. 